\title{
COPD cases detected by spirometry on world COPD day event in Bursa
}

\author{
Ozlem Sengoren Dikis ${ }^{1}$, Seyhan Us Dülger ${ }^{1}$, Mehmet Karadag ${ }^{2}$, Hakan Demirci $^{3}$ \\ ${ }^{1}$ Department of Pulmonary Medicine, Sevket Yilmaz Training and Research Hospital, Bursa, Turkey \\ ${ }^{2}$ Department of Pulmonary Medicine, Uludag University Medicine School, Bursa, Turkey \\ ${ }^{3}$ Department of Family Medicine, Sevket Yilmaz Training and Research Hospital, Bursa, Turkey
}

\begin{abstract}
Objective. We organized a 'World Chronic Obstructive Pulmonary Disease (COPD) Day' event to raise awareness in society of the disease and we evaluated the results of the activity. Method. Volunteers (n = 79) consisted of persons shopping in a famous shopping center in Bursa. A short past history of COPD from the volunteers was requested. Pulmonary Function Tests were performed by spirometry and a Fagerstrom test for dependence was filled out by the volunteers. In cases where airway obstruction was detected, physicians performed a reversibility test. Result. Of the 79 volunteers who participated in the study, 39 cases were detected to have airway obstruction. Of those, 15 patients had been previously diagnosed with COPD; on the other hand, 24 patients were diagnosed with COPD for the first time. There was no newly diagnosed COPD patient among the nonsmokers. The prevalence of COPD was $49.36 \%$ and the awareness rate was only $38.46 \%$. Conclusion. In the present study, we determined that the COPD prevalence is $49.36 \%$, which is quite high when compared with the previous studies published in Turkey. In such a cross sectional study, volunteers would probably be composed of persons who would have the disease at higher rates. We observed that there was a low awareness of COPD among smokers. Events that are aiming to increase the social awareness to such a particularly prevalent disease should be encouraged.
\end{abstract}

Eur Res J 2015;1(2):61-65

Keywords: COPD, awareness, smoking, reversibility

\section{Introduction}

Chronic Obstructive Pulmonary Disease (COPD) is a frequent public health problem. Besides its frequency, its negative effect on quality of life and its high economic cost increase its importance. This disease ranks among the top in the DALY range
(Disability Adjusted Life Years), which is described as the total of early deaths and years lost due to disability.

COPD is declared to be the $3^{\text {rd }}$ cause of death all over the world [1]. Similarly, in our country respiratory 
system diseases are reported to be the 3rdranked cause of death [2]. Despite the significant decrease in other prominent causes of death in recent years, chronic diseases are very much on the map now and are responsible for many deaths [3].

While COPD frequency is increasing all over the world with the advanced average age, it is also decreasing due to reductions in air pollution and the increasing fight against tobacco. In a study made in our country in 2004 (BOLD-Adana), the prevalence of COPD in adults over age 40 was $19.1 \%$ [4].

Every year, the 3rd Wednesday in November is celebrated as World COPD day and the slogan of the 2013 World COPD day was 'Not too late'. In this context, in order to make the public more conscious of COPD, we made spirometric measurements in a shopping mall in Bursa to evaluate the COPD situation and we informed the people about COPD. Our aim in this study was also to evaluate the data we obtained.

\section{Materials and Methods}

On World COPD day 2013, volunteers between the ages of 18 and 65 among the customers of a shopping mall in Bursa city center were involved in our study. Weight and height of the individuals were properly measured. Their Body Mass Index (BMI) values were calculated by a weight $(\mathrm{kg}) /$ height $\left(\mathrm{m}^{2}\right)$ formula. COPD history, shortness of breath, cough and expectoration complaints and smoking status of the volunteers were requested. The smoking group was given a Pulmonary Function Test (PFT) and a Fagerstrom Addiction Test. Nonsmoking volunteers were only given the Pulmonary Function Test. Patients whose fixed ratio measurement was FEV1/FVC $<0.7$ were given the reversibility test. For the reversibility test, spirometric measurements were made before and 20 minutes after inhalation of $400 \mu \mathrm{g}$ salbutamol with a metered dose inhaler. In the evaluation of bronchodilator response, reversibility was calculated based on the expected FEV1 percentage of $12 \%$ and the absolute change between both FEV1 measurements as over $200 \mathrm{ml}$. Besides the PFT evaluation of the patients in terms of Asthma and COPD Overlap Syndrome (ACOS) diagnosis, symptoms such as shortness of breath and cough, allergy histories and asthma histories determined by a doctor in their childhood and young adulthood period were searched. There was no patient in the event group that may have been ACOS. The ones whose PFT results, symptoms and background data were in accordance with the specified criteria were accepted as COPD.

Ethical approval for the study was obtained from the Sevket Yilmaz Training and Research Hospital

Ethics Committee. Statistical analysis was made with the SPSS (13.0) package program. Arithmetic means ( \pm standard deviation) and percentages were calculated.

\section{Results}

Seventy-nine volunteers regardless of sex were allowed to participate in our study. While $43(54.4 \%)$ were active smokers, $36(45.6 \%)$ were nonsmokers. 21 of 43 active smokers $(48.8 \%)$ were female and $22(51.2 \%)$ were male; their average age was $37.34 \pm 11.2$ (Table1).

The average Body Mass Index was 26.06 \pm 5.02 $\mathrm{kg} / \mathrm{m} 2$; the Fagerstrom Addiction Value average was $4.48 \pm 2.05$. In the smoking group, 19 (44.2\%) patients had no complaints or symptoms and their spirometer values were normal (Figure 1).

Post-bronchodilator FEV1/FVC ratio in twentyfour patients $(55.8 \%)$ was below 70 and FEV1 (\%) was $67.04 \pm 17.99$ and FEV1/FVC was $62.89 \pm$ 6.08 (Figure 2). These patients also had complaints such as shortness of breath, cough and expectoration. Only 6 of the patients were previously aware of their illness $(20 \%)$.

Twenty-four of 36 non-smoking patients $(66.7 \%)$ were female and 12 were $(33.3 \%)$ male. The average age was $47.86 \pm 15$; the average Body Mass Index was $26.67 \pm 4.39 \mathrm{~kg} / \mathrm{m} 2$. In this group, 9 patients had a history of COPD. There was no new COPD diagnosis in the non-smoking group. While 15 patients out of 79 were aware of their COPD disease, 14 new cases were detected. These 24 patients were given Medical Research Council (MRC) staging. 13 patients $(54.2 \%)$ were assessed as stage $1 ; 9$ patients $(37.5 \%)$ as stage 2 and 2 patients $(8.3 \%)$ as stage 3. According to COPD classification, 9 patients (37.6\%) were reported as group A; 8 patients $(33.3 \%)$ as group B; 5 patients $(20.8 \%)$ as group $\mathrm{C}$; and 2 patients $(8.3 \%)$ as group D (Figure 3 ).

Awareness of the disease was calculated as $38.46 \%$. COPD prevalence in the study group was $49.36 \%$. 
Table 1. Smoking habits by gender

\begin{tabular}{llll}
\hline Feature & Male & Female & Total \\
\hline Smokers & $22(54.4 \%)$ & $24(66.7 \%)$ & 46 \\
Nonsmokers & $21(45.6 \%)$ & $12(33.3 \%)$ & 33 \\
Total & 43 & 36 & 79 \\
\hline
\end{tabular}

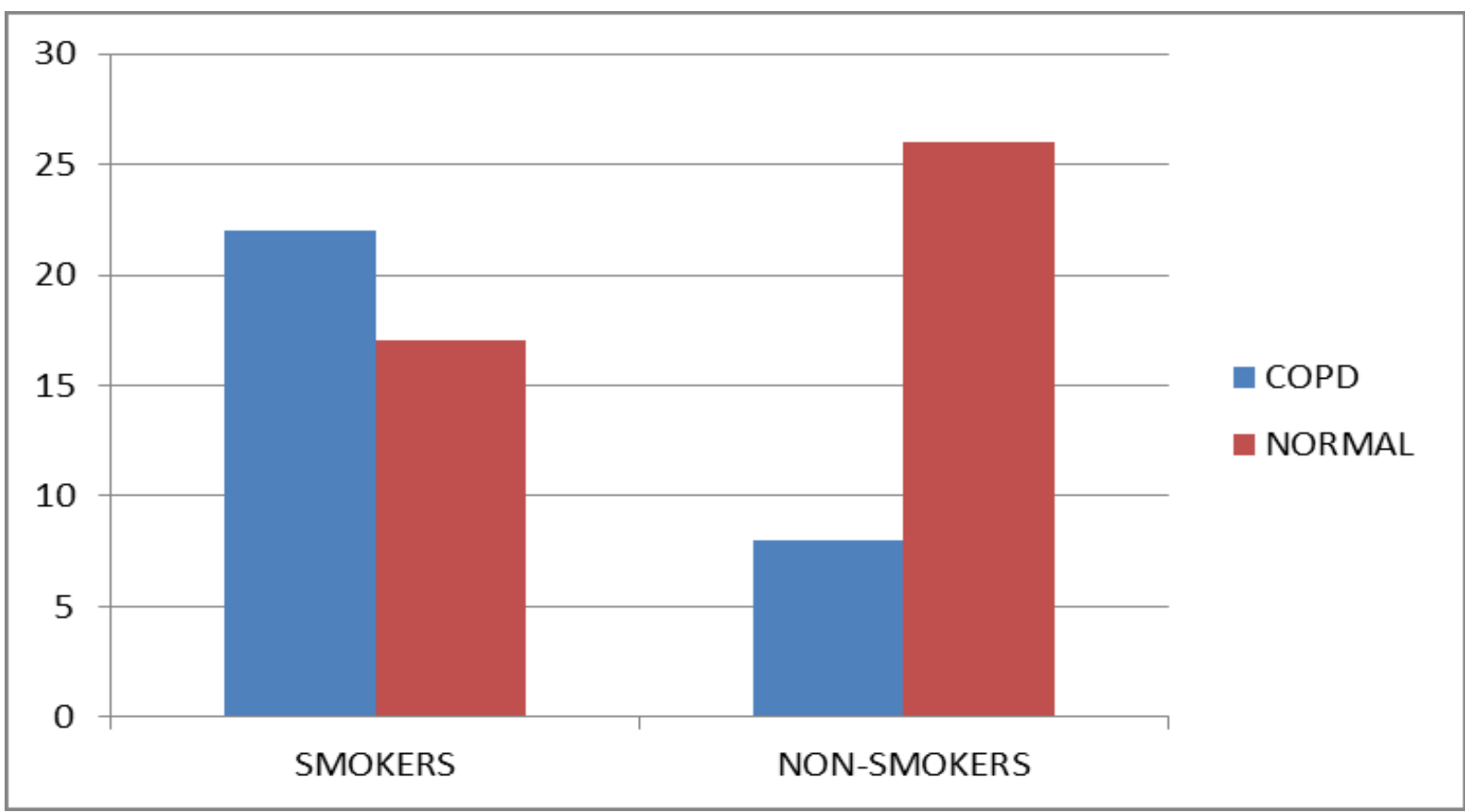

Figure 1. Chronic obstructive pulmonary disease distribution among smokers and non-smokers

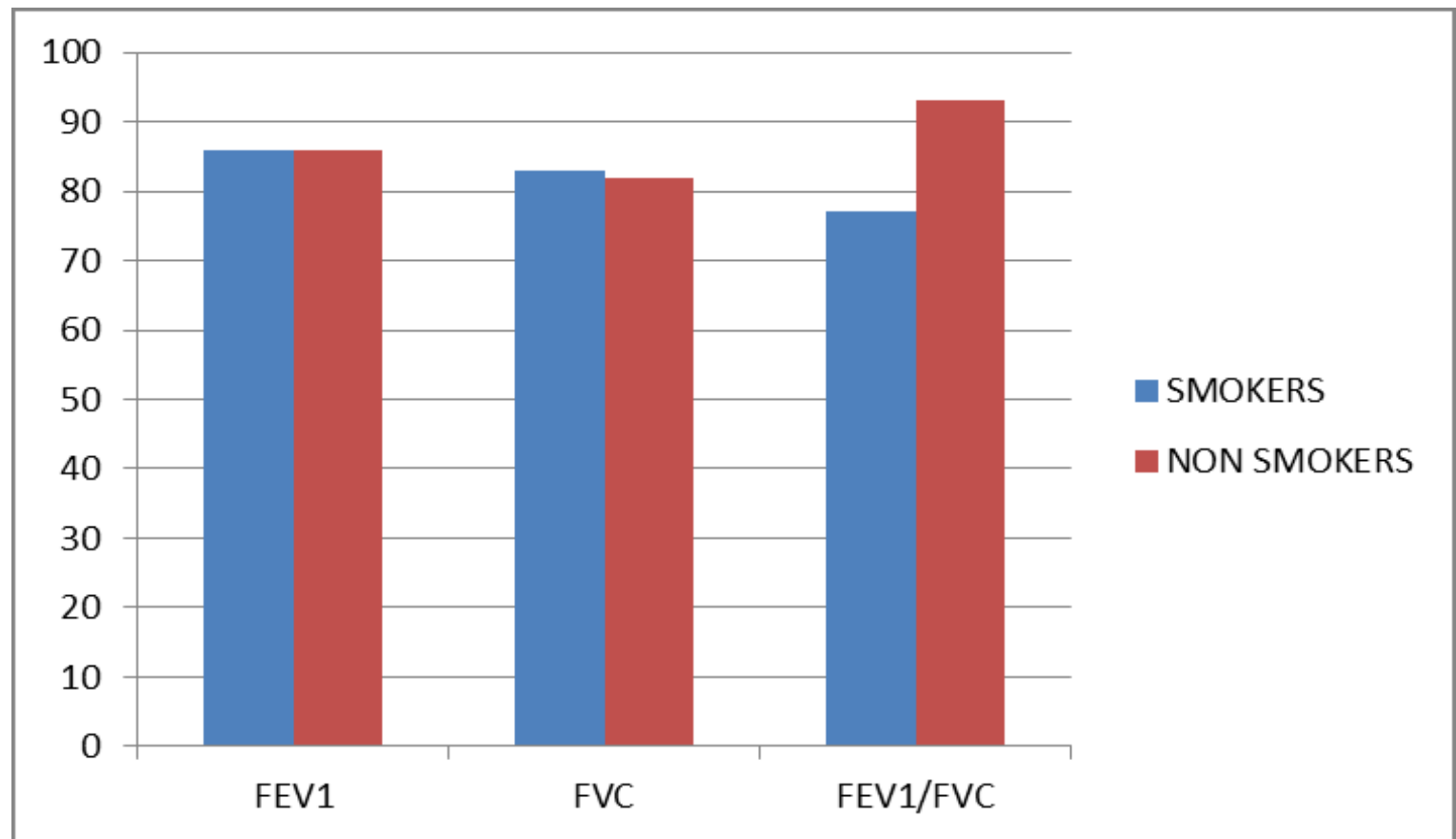

Figure 2. Pulmonary function test results of smokers and non-smokers 


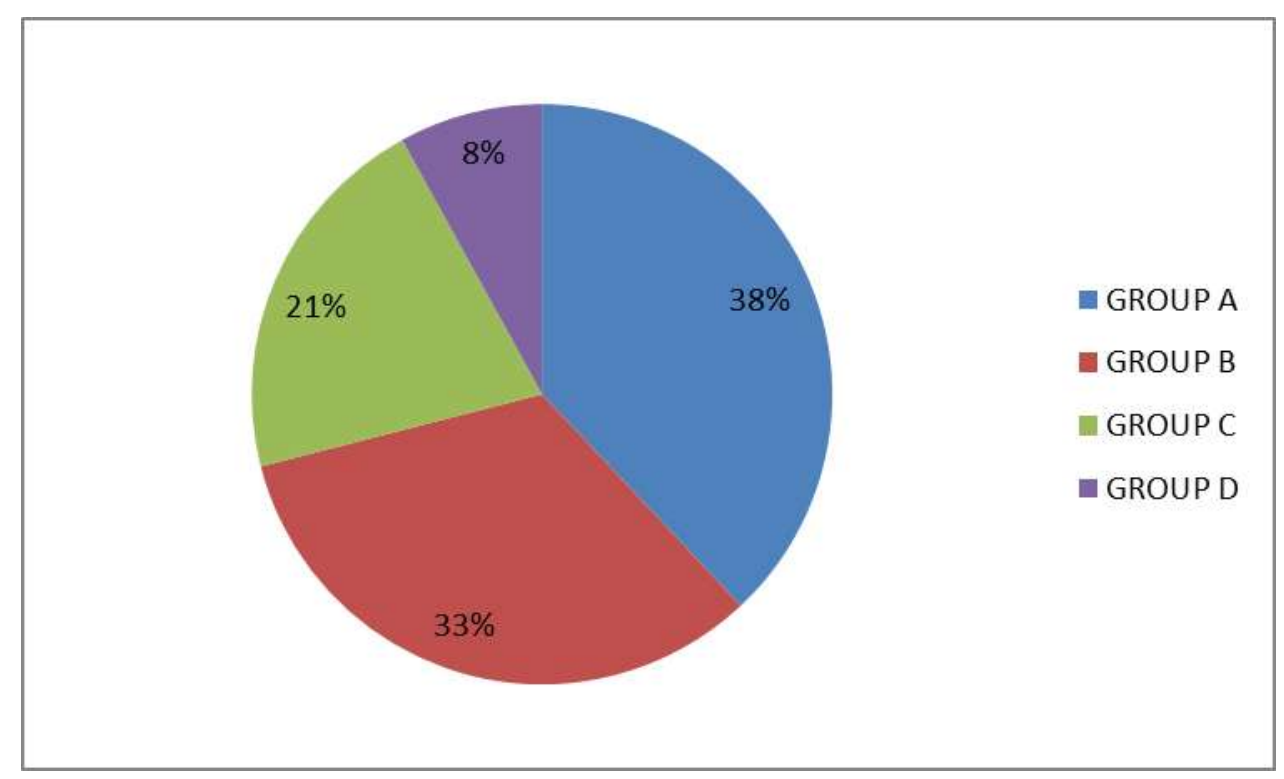

Figure 3: Chronic Obstructive Pulmonary Disease severity

\section{Discussion}

In our country, there are significant efforts against tobacco as a health policy. Lately, there has been an effort to prevent an increase in smoking by the implementation of the $100 \%$ smoke-free project. The fact that fuel used for cooking at home now keeps people from biomass exposure, use of natural gas primarily for heating, and more professional exhaust inspections are all positive efforts to reduce air pollution. COPD frequency varies in the studies made in our country. While the prevalence in the BOLD study was $19.1 \%$, it was $11.5 \%$ (5.9\% female and $15.1 \%$ male) in a study made by Deveci et al. in Elazig [7]. In all these studies, COPD description and staging were made according to the guidelines of the Global Initiative for Chronic Obstructive Lung Disease (GOLD) [8]. The COPD frequency among volunteers was $49.3 \%$ in our study. This value, which is higher than the ratio found in previous studies in our country, may result from an inaccurate randomization. In such cases, those who think that they have a problem may have preferred to participate in the study.

It is suggested that neither the society nor health employees have sufficient knowledge about COPD.
It is also known that only 10-30\% of COPD patients are aware of their illness. In this context, it is important in terms of public health to create an awareness of COPD in society and to emphasize that COPD is a preventable and treatable disease. In this study, we tried to raise consciousness among the public and to discuss the values obtained in the framework of such an event.

Fourty-three out of 79 participants in this study (54.4\%) were still active smokers. According to the "Global Adult Tobacco Research" made by the Turkey Statistics Institute in 2010, 31.2\% of adults over age 15 in our country (47.9\% in males, $15.2 \%$ in females)still use tobacco [9]. 24 (55.8\%) patients who smoked and had COPD disease were asked about their COPD history, but only 6 of them (25\%) were aware of their disease (25\%). The smoking ratio in adults in our study was higher than in the literature [9]. The reason for this may be the fact that especially active smokers may have participated in our study because they wondered about their state of health. However, 9 patients $(25.7 \%)$ in the non-smoker group had COPD disease. 


\section{Conclusion}

According to the results we obtained, COPD is a frequent disease in our country and smokers are largely not aware of their status. We believe that events such as this one may be beneficial for reaching patients and moreover may play an active role as awareness-raising efforts in society.

\section{References}

[1] Lozano R, Naghavi M, Foreman K, Lim S, Shibuya K, Aboyans V, Abraham J, Adair T, Aggarwal R, Ahn SY, et al. Global and regional mortality from 235 causes of death for 20 age groups in 1990 and 2010: a systematic analysis for the Global Burden of Disease Study 2010. Lancet. 2012;380(9859):2095-128. [2] Olum nedeni istatistikleri, 2010, 2011, 2012. TUIK Haber Bulteni 2013; Sayi: 15847.

[3] Paczek L, Nowak M. The paradox of the 21 st century -is there really an epidemic of most common killers? Int Gen Med. 2011;4:799802 .

[4] Kocabas A, Hancioglu A, Turkyilmaz S, et al. Prevalence of COPD in Adana, Turkey (BOLD-Turkey Study). Proceedings of the American Thoracic Society 2006; 3 (Abstract Issue): A543. [5] Turkiye Kronik Hastaliklar ve Risk Faktorleri Sikligi Calismasi. Saglik Bakanligi Yayin No: 909, Ankara, 2013.

[6] Buist AS, McBurnia MA, Vollmer WM, et al. BOLD Collaborative Research Group. International variation in the prevalence of COPD (The BOLD Study): A population-based prevalence study. Lancet. 2007; 370:741-50.

[7] Deveci F, Deveci SE, Turkoglu S, Turgut T, Kirkil G, Rahman $\mathrm{S}$, et al. The prevalence of chronic obstructive pulmonary disease in Elazig, Eastern Turkey. Eur J Intern Med. 2011;22:172-6. [8] Global Strategy for the Diagnosis, Management, and Prevention of Chronic Obstructive Pulmonary Disease Revised 2011. Global Initiative for Chronic Obstructive Lung Disease (GOLD). http://www.goldcopd.org

[9] Turkish Statistical Institute Global Adult Tobacco Survey, 2010. 